\title{
Efficacy of Acrylic Splint in Management of Internal Derangement of Temporomandibular Joint
}

\author{
Ahmed MA ${ }^{1}$, Rahman $\mathrm{QB}^{1}$, Uddin $\mathrm{MW}^{1}$, Asaduzzaman $\mathrm{M}^{1}$, Ali $\mathrm{MH}^{2}$ \\ ${ }^{1}$ Department of Oral \& Maxillofacial Surgery, Bangabandhu Sheikh Mujib Medical University, \\ Dhaka, Bangladesh \\ ${ }^{2}$ Department of Oral \& Maxillofacial Surgery, Dhaka Dental College, Dhaka, Bangladsesh
}

\begin{abstract}
e-mail: drayazahmed31@yahoo.com

Occlusal splint plays a great role in the treatment of internal derangement of temporomandibular joint. Temporomandibular disorders affect $25 \%$ of the population of the world. The purpose of the study was to elucidate the effectiveness of occlusal splint in reduction of pain, increase mouth opening, elimination of clicking sound. This randomized controlled clinical trial was done on 26 patients in two groups. Group A received occlusal splint and Group B received medications with supportive care. Monthly follow-up was done for a period of four months. In Group A and Group B, preoperative mean of mouth opening were $36.31 \mathrm{~mm}$; and $39.77 \mathrm{~mm}$. pain score $4.54 \mathrm{~cm}$, clicking in $76.9 \%$ and $84.6 \%$ patients respectively. After 4 months of follow- up mouth opening $50.69 \mathrm{~mm}$ and $43.15 \mathrm{~mm}$, pain score $0.154 \mathrm{~cm}$ and $0.69 \mathrm{~cm}$, clicking $30.8 \%$ and $76.9 \%$ patients in both groups respectively. It may be conclude that the occlusal splint is highly efficient than medication and supportive care for managing of internal derangement of temporomandibular joint.
\end{abstract}

Key words: Temporomandibular Joint disorder, Internal derangement, Occlusal splint.

\section{Introduction}

The prevalence of clinically significant TMJ related jaw pain is 5\% among the general population. Approximately $2 \%$ of the general population seeks treatment for TMJ-related symptoms. ${ }^{1}$ The temporomandibular joint is an important part of lower jaw except which mastication is impossible and temporomandibular system consists of temporomandibular joint (TMJ) and the associated neuromuscular system. ${ }^{2}$ The most frequent structural cause of temporomandibular joint disorder is internal derangement. ${ }^{3}$ The term Internal Derangement (ID) of TMJ has been defined as an abnormal relationship between the articular disc and the mandibular condyle, the fossa and the articular eminence. ${ }^{4}$ Signs and symptoms of ID affect between $4 \%$ and $28 \%$ of the adult population, with a higher frequency found in women. The factors responsible for this predominance are not known. ${ }^{5}$

If the disc slips out of place or is displaced, it can prevent the proper movement of the condyle and cause dysfunction. The disc can degenerate, becoming misshapen or even torn. Because the deranged joint will continue to try to function, even in an impaired manner. Internal derangement disorders often get progressively worse with time. $^{6}$

Aetiology of these disorders includes Trauma (such as injuries from eating, excessive jaw opening and during dental treatment); bruxism, malocclusion (causes inappropriate pressure on the joint); stress and psychiatric illness. ${ }^{7}$

Internal derangement (ID) can cause a wide range of pain in the jaw joints which is the most frequently taking place symptom. ${ }^{6}$ In disc displacement with reduction, clinically there is relatively normal range of movement with restriction only associated with pain. Discal movement can be felt by palpation of the joints during opening and closing. Deviation in the opening pathway are common. ${ }^{8}$ Internal derangement of TMJ was diagnosed by the research diagnostic criteria for temporomandibular disorders (RDC/TMD) established by a group of American researchers in $1992^{9}$ such as a) Disc displacement with 
reduction: manifested by absent of pain in the joint; reproducible click on excursion with either opening or closing click, with click on opening and closing (unless excursive click confirmed): i) click on opening occurs at $\geq 5 \mathrm{~mm}$ interincisal distance than closing, ii) clicks eliminated by protrusive opening; b) Disc displacement without reduction with limited opening: characterized byhistory of locking or catching that interfered with eating; absence of TMJ clicking; unassisted opening (even painful) $\leq 35 \mathrm{~mm}$ and passive stretch $\leq 4 \mathrm{~mm}$; and contralateral excursion $<7 \mathrm{~mm}$ or uncorrected ipsilateral deviation on opening; and c) Disc displacement without reduction without limited opening characterized by history of locking or catching that interfered with eating, the presence of TMJ sounds excluding DDR clicking unassisted opening (even painful)> $35 \mathrm{~mm}$ and passive stretch $>4 \mathrm{~mm}$, and contralateral excursion $\geq 7 \mathrm{~mm}$ (Dworkin SF. LeResche L. 1992). Different treatment modalities have been advocated. Conservative treatment includes homecare practices (soft diet, jaw exercises, physical therapy, steam baths, muscle massage). ${ }^{10}$ Occlusal adjustment (repositioning the mandible in a centric position by prosthodontic or orthodontic means and/or occlusal equilibration), ${ }^{11}$ analgesia and psychotropic medication (such as NSAIDs and diazepam), ${ }^{12}$ splint therapy ${ }^{13}$ and other treatment modalities (ultrasound, soft laser, diathermy, infrared). ${ }^{14}$ Surgical treatment (irreversible) includes three different treatments for internal derangement of TMJ i.e. discoplasty, discectomy with or without replacement of the disc with a Proplast-Teflon interpositional implant. ${ }^{15}$

An acrylic splint is a useful device for the treatment of ID. It is relatively simple to manufacture and use, reversible, non-invasive and costs less than other treatments, portable and generally have a low complication rate and it has also diagnostic value. However, the mechanism by which occlusal splints work in alleviating signs and symptoms of such a disorder is still controversial. ${ }^{16}$ Some theories that tried to explain its mechanism include alteration or improvement of occlusal condition, change in peripheral (motor or afferent) impulses to the central nervous system, alteration or raise in the vertical dimension, alteration of the temporo-mandibular joint (TMJ) condylar position and increase in the cognitive awareness. ${ }^{17}$
Aim of the study was to elucidate the effectiveness of acrylic occlusal splint therapy in the treatment of Internal Derangement of Temporomandibular joint over other nonsurgical procedure (Analgesic, muscle relaxant and supportive care).

\section{Materials and Methods}

This randomized controlled clinical trial study done in the department of Oral \& Maxillofacial Surgery of Bangabandhu Sheikh Mujib Medical University, Dhaka, Bangladesh from October, 2013 to September, 2014. Pain, mouth opening, clicking sound of the patients suffering from ID of TMJ were evaluated. Twenty six patients were randomly selected into two groups. Group A (13 patients) were given acrylic splint therapy and group B (13 patients) were given medication and supportive care. Adult patients aged 20-60 years having criteria of internal derangement of TMJ were selected.

Prior to the commencement of the study, the research protocol was approved by the ethical institutional review board of BSMMU, Dhaka. The aims and objectives of the study along with its procedures, risk and benefits of the study were explained to the patient in easily understandable local language. Then informed consent was taken from each patient.

The collected data were summarized in terms of tables and diagrams. The arithmetic mean and standard deviation were calculated. Data were analyzed in SPSS version 20. The unpaired t test was used to find the significant differences of the variables- mouth opening and pain score and chi-square test for clicking sound in between the two groups.

A detailed history and findings of the clinical examination of each patient were recorded. After taking history, maximum comfortable mouth opening of all patients was recorded. TMJ examination included assessment of clicking, tenderness at rest and during various jaw movements (opening, closing, right and left lateral, protrusion and retrusion) and deviation during opening and closing movements. Tenderness of the muscles of mastication and the neck muscles were assessed by means of digital palpation, Extraoral masticatory muscles such as the temporalis and masseter were palpated with a digital pressure. The medial and lateral pterygoid mus- 
cles were evaluated by functional manipulation. Clicking was confirmed by stethoscope.

After thorough history and clinical examination, 26 patients were selected for this study according to inclusion and exclusion criteria. Randomization were done by lottery. Thirteen patients were given acrylic splint and another 13 patients have same criteria were given analgesic, muscle relaxant and supportive care.

Alginate impressions of the both arches were performed and a master cast was fabricated for each patient. After taking bite registration on each patient's mouth, articulation of model was done. Then undercuts of upper arch on the model were blocked out. Wax pattern for occlusal splint was done. It was followed by processing. After curing, remounting followed by correction and occlusal adjustment was done. After finishing and polishing the splint was then disinfected with $2 \%$ glutaraldehyde and then inserted in upper arch of the patient's mouth.

The splint was worn for 4 months in the following manner:

At the 1st week: patients were instructed to wear the splint for only 2 hours at the first day, then increasing the period of wearing the splint gradually by more 2 hours daily to reach 14 hours/day at the end of the 1st week. At the 2nd week: splint was worn constantly for 14 hours daily. At the 3rd week: patients were instructed to increase the period of wearing the splint again gradually by more 2 hours daily to reach 24 hours /day except the meal time and keep this period of wearing till the end of 4th month. Patients were recalled monthly for 4 months to check the condition of patient. All the parameters for TMJ functions were assessed at all follow-up periods.

\section{Results}

Twenty six patients according to inclusion and exclusion criteria were selected randomly. Of them, thirteen patients were under Group A, who received given occlusion splint and other thirteen patients were under Group B who received analgesic, muscle relaxant and other supportive care. Most of the patients in this study were within $3^{\text {rd }}$ decade both group A (92.2\%) and group B $(46.2 \%)$.

Most of patients in both groups were male. Group A , 92.2\% male and group B , 61.5\% male were affected with ID of TMJ. Females were more in group B (38.5\%). Majority of the patients coming to the department with ID were male.

Different tables have been given below to show their distribution and treatment result:

Table I: Age distribution of the study patients in two studied group $(n=26)$

\begin{tabular}{cccc}
\hline Age & $\begin{array}{c}\text { Group A } \\
\text { (Splint Therapy) } \\
(\mathbf{n = 1 3}) \mathbf{N o} .(\%)\end{array}$ & $\begin{array}{c}\text { Group B (Medi- } \\
\text { cation) } \\
(\mathbf{n = 1 3}) \mathbf{N o}(\%)\end{array}$ & $\boldsymbol{p}$ \\
\hline $20-30$ yrs & $9(69.2 \%)$ & $6(46.2 \%)$ & \\
$31-40$ yrs & $1(7.7 \%)$ & $2(15.4 \%)$ & \\
$41-58$ yrs & $3(23.1 \%)$ & $5(38.5 \%)$ & \\
Total & $13(100.0 \%)$ & $13(100.0 \%)$ & \\
Mean \pm SD & $32.92 \pm 1090$ & $36.00 \pm 14.21$ & $0.54^{\mathrm{ns}}$ \\
Range & $(20-58)$ & $(20-58)$ & \\
\hline
\end{tabular}

$p$ value reached from independent student $\mathrm{t}$-test, $\mathrm{ns}=$ Not significant

Table II: Sex distribution of the study patients $(n=26)$

\begin{tabular}{llll}
\hline \multicolumn{1}{c}{ Sex } & $\begin{array}{c}\text { Group A } \\
\text { (Splint Therapy) } \\
(\mathbf{n = 1 3}) \text { No. }(\%)\end{array}$ & $\begin{array}{c}\text { Group B (Medi- } \\
\text { cation) } \\
(\mathbf{n = 1 3}) \mathbf{N o}(\boldsymbol{\%})\end{array}$ & $\boldsymbol{p}$ \\
\hline Male & $9(68.2 \%)$ & $8(61.5 \%)$ & $0.68^{\mathrm{ns}}$ \\
Female & $4(30.8 \%)$ & $5(38.5 \%)$ & \\
Total & $13(100.0 \%)$ & $13(100.0 \%)$ & \\
\hline$p$ value reached from chi-square test, ns $=$ Not significant &
\end{tabular}

An average $88.46 \%$ patient suffering from ID of TMJ are due to trauma, only $11.58 \%$ patients are due to para-functional habit (bruxism) in table III

Table III: Distribution of patients according to aetiology

\begin{tabular}{ccccccc}
\hline $\begin{array}{c}\text { Total no. } \\
\text { of patient }\end{array}$ & Etiology & $\begin{array}{c}\text { Group A } \\
\text { No. of patient }\end{array}$ & $\%$ & $\begin{array}{c}\text { Group B } \\
\text { No. of patient }\end{array}$ & $\begin{array}{c}\text { Mean of } \\
\text { percentage }\end{array}$ \\
\hline 13 & Trauma & 10 & 76.92 & 13 & 100 & 88.46 \\
13 & Bruxism & 3 & 23.08 & 0 & 0 & 11.58 \\
\hline
\end{tabular}

The preoperative restriction in $\mathrm{MMO}$ ranged from 28 to $40 \mathrm{~mm}$ (Mean 36.31 mm) in Group A and 30 to $44 \mathrm{~mm}$ (Mean $39.77 \mathrm{~mm}$ ). With the time there was gradual improvement of mouth opening. Each month there was improvement of MO (mouth opening) with each treatment. After one month the improvement was not significant. The mean value was 38.77 in group A and 41.15 in Group B. But after 4 months, there was significant improvement in MO by Group A (i.e Occlusal splint). The results were statistically significant ( $p=0.001)$, shown in table IV

Table IV: Comparison of mouth opening at baseline and other follow up in two studied group $(n=26)$

\begin{tabular}{llll}
\hline $\begin{array}{l}\text { Mouth open- } \\
\text { ing }(\mathbf{m m})\end{array}$ & $\begin{array}{l}\text { Group A } \\
(\text { Splint Therapy) } \\
(\mathbf{n}=\mathbf{1 3}) \text { Mean } \pm \text { SD }\end{array}$ & $\begin{array}{l}\text { Group B (Medica- } \\
\text { tion) } \\
(\mathbf{n}=\mathbf{1 3}) \text { Mean } \pm \text { SD }\end{array}$ & $\boldsymbol{p}$ value \\
\hline At baseline & $36.31 \pm 6.14$ & $39.77 \pm 6.30$ & $0.169^{\mathrm{ns}}$ \\
After 1 month & $38.77 \pm 5.13$ & $41.15 \pm 5.60$ & $0.269^{\mathrm{ns}}$ \\
After 2 month & $41.92 \pm 4.79$ & $41.92 \pm 5.30$ & $1.00^{\mathrm{ns}}$ \\
After 3 month & $46.46 \pm 4.37$ & $42.31 \pm 5.07$ & $0.035^{\mathrm{s}}$ \\
After 4 month & $50.69 \pm 4.85$ & $43.15 \pm 5.03$ & $0.001^{\mathrm{s}}$ \\
\hline$p$ value reached from unpaired t test, $\mathrm{s}=$ significant & $\mathrm{ns}=$ Not significant
\end{tabular}


Pain score was measured by VAS (Visual analogue scale). Statistical analysis was done by unpaired $t$ test. Analysis showed gradual relief of pain with time in both group of treatment. Preoperative pain scores ranged from 2 to 8 (Mean 4.45) in both group of treatment. But Group A showed significant relief of pain (baseline mean $=4.54$ ) after 1 month (mean =1.92) followed by gradual improvement of condition. After 3 months group A (mean=0.38) showed significant pain reduction in comparison to Group B (mean 1.46) $(p=0.002)$. After 4 months treatment, there was a maximum pain reduction in both groups with the reduction in the mean VAS for pain 0.154 and 0.69 in group A and Group B respectively. After 4 months of treatment the result was statistically significant result $(p=0.04)$.

Table V: Comparison of pain at baseline and other follow up in two studied group $(\mathrm{n}=26)$

\begin{tabular}{cccc}
\hline Pain score & $\begin{array}{c}\text { Group A } \\
\text { (Splint Therapy) } \\
(\mathbf{n = 1 3 ) M e a n} \pm \text { SD }\end{array}$ & $\begin{array}{c}\text { Group B (Medi- } \\
\text { cation) } \\
(\mathbf{n}=\mathbf{1 3}) \text { Mean } \pm \text { SD }\end{array}$ & $\boldsymbol{p}$ value \\
\hline At baseline & $4.54 \pm 2.73$ & $4.54 \pm 1.71$ & $1.0^{\mathrm{ns}}$ \\
After 1 month & $1.92 \pm 1.98$ & $3.00 \pm 1.08$ & $0.09^{\mathrm{ns}}$ \\
After 2 month & $1.23 \pm 1.17$ & $2.00 \pm 0.82$ & $0.06^{\mathrm{ns}}$ \\
After 3 month & $0.38 \pm 0.51$ & $1.46 \pm 0.97$ & $0.002^{\mathrm{s}}$ \\
After 4 month & $0.154 \pm .38$ & $0.69 \pm .85$ & $0.04^{\mathrm{s}}$ \\
\hline$p$ value reached from unpaired t test, $\mathrm{s}=$ significant $\mathrm{ns}=$ Not significant
\end{tabular}

Amongst the 13 patients, 10 (76.9\%) had clicking sound before treatment in Group $\mathrm{A}$ and 11(84.6\%) had clicking in Group B. Every month there was improvement of the condition in Group A in comparison to Group B. After 4 months, the treatment showed significant improvement $(p=0.01)$. There was improvement clicking with splint is $69.2 \%$ (9 patients) in comparison to treatment Group B where improvement was $23.1 \%$ (3 patients).

Table VI: Comparison of clicking status at baseline and other follow up in two studied group $(\mathrm{n}=26)$

\begin{tabular}{llll}
\hline $\begin{array}{l}\text { Clicking } \\
\text { status }\end{array}$ & $\begin{array}{l}\text { Group A } \\
\text { (Splint Therapy) } \\
\text { (n=13)No. (\%) }\end{array}$ & $\begin{array}{l}\text { Group B (Medi- } \\
\text { cation) } \\
\text { (n=13)No. (\%) }\end{array}$ & p value \\
\hline $\begin{array}{l}\text { At baseline } \\
\text { Present }\end{array}$ & $\begin{array}{l}\text { 10(76.9\%) } \\
\text { Absent }\end{array}$ & $\begin{array}{l}11(84.6 \%) \\
2(23.1 \%)\end{array}$ & $0.62^{\text {ns }}$ \\
After 1 month & & $115.4 \%)$ & \\
Present & $9(69.2 \%)$ & $1(84.6 \%)$ & $0.35^{\text {ns }}$ \\
Absent & $4(30.8 \%)$ & $2(15.4 \%)$ & \\
After 2 month & & $11(84.6 \%)$ & $0.08^{\mathrm{s}}$ \\
$\begin{array}{l}\text { Present } \\
\text { Absent }\end{array}$ & $7(53.8 \%)$ & $2(15.4 \%)$ & \\
After 3 month & $6(46.2 \%)$ & $10(76.9 \%)$ & $0.01^{\mathrm{s}}$ \\
$\begin{array}{l}\text { Present } \\
\text { Absent }\end{array}$ & $4(30.8 \%)$ & $3(23.1 \%)$ & \\
After 4 month & $9(69.2 \%)$ & $10(76.9 \%)$ & $0.01^{\mathrm{s}}$ \\
$\begin{array}{l}\text { Present } \\
\text { Absent }\end{array}$ & $4(30.8 \%)$ & $3(23.1 \%)$ & \\
\hline
\end{tabular}

$p$ value reached from chi-square test, $\mathrm{s}=$ significant $\mathrm{ns}=$ Not significant

\section{Discussion}

Amongst the 13 patients allocated for splint $69.3 \%$ were male and $30.7 \%$ were female. Among treatment Group-B, $61.5 \%$ patients were male and $38.5 \%$ patients were female. One of the significant findings of this study was that $88.46 \%$ of the patients had trauma. Bruxism was the second cause. Nocturnal bruxism is a parafunctional habit of mouth, consisting of involuntary rhythmic or spasmodic nonfunctional grinding or clenching of teeth. This may lead to occlusal trauma. ${ }^{18}$

The OS was effective in this regard as results showed that patients with ID showed a significantly better response to OS treatment. Trauma was considered one of the main causes of ID. It may be macrotrauma or microtrauma (bruxism). ${ }^{8}$ Majority of the patients gave history of early onset of ID.

There is clinical evidence supporting the existence of disc displacement in TMJ internal derangement. This study compared the treatment outcomes of the application of occlusal splint (Group A) with medication (analgesic, muscle relaxant with or without anxiolytic as well as supportive care (Group B). Study parameters were mouth opening (MO), pain, clicking sound in each group. Within one year of study of patients followed up period was four months.

As a result, all groups in this study showed improvement in pain, maximum comfortable opening, and clicking sound. An association was observed between the Groups and period of normal state. For $\mathrm{MO} \geq 41 \mathrm{~mm}$, there was a significant difference by treatment. Group B took longer time to achieve normal state than group A. A relationship has been found between pain reduction and mouth opening. After three months when VAS score have been reduced to mean0.38 in Group A and 1.46 in Group B there was improvement of mouth opening mean $46.46 \mathrm{~mm}$ and $42.31 \mathrm{~mm}$ for Group A and Group B respectively. It suggests that pain reduction improves mouth opening.

In the current study, the results of the pain levels (VAS) showed that there was a significant improvement in the pain scores between all time intervals with the highest values of improvement from $3\left(p=0.002^{\mathrm{s}}\right)$ to 4 months $\left(p=0.04^{\mathrm{s}}\right)$ post- 
operative intervals. In a study done in 2003, it was found that occlusal splints had decreased the VAS scores and the number of painful muscles during a six-week follow-up study in patients with myofascial pain. ${ }^{19}$

Different studies shows OS causes faster improvement with a $83.4 \%$ healing rate,$^{18}$ pain reduction in $69.2 \%$ of patients with anterior disc displacement with reduction ${ }^{20}$ and long-term follow-up (18-20 years) of reduction of pain in $50 \%$ of TMD patients. ${ }^{21}$

Clicking results from anterior disc displacement. Study showed significant reduction of joint click after the use of OS. ${ }^{18}$ Another study showed that after treatment of early onset TMD with OS for 6 weeks, the mean reduction of symptoms was significant; however, clicking and improvement of clicking required a minimum of 5 months of OS therapy. ${ }^{22}$ Thus, elimination of clicking needs more time to heal than other symptoms of TMD. $^{23}$

In this study, in $46.1 \%$ of the patients clicking was eliminated completely with occlusal splint whereas $7.6 \%$ was improved in Group B like the study which showed clicking was eliminated completely among $50 \%$ of the patients. ${ }^{23}$

\section{Conclusion}

Although different study shows that the rate of internal derangement is higher in female but in this population, ID was higher in males because the number of patients visited with ID was more. Treatment of early ID with OS was more effective than treatment with medication with supportive care. Trauma had a significant aetiologic role in ID. The conventional acrylic occlusal splint therapy is a much safe and effective mode for conservative therapy of patients with ID of TMJ. It is reversible, simple, and least cost therapy with adequate patient compliance. So, this study supports using acrylic occlusal splint therapy in the management of ID for better long-term results than conventional medication with supportive care.

\section{Reference}

1. Girish B, Giraddi A, Siddaraju, Bimleshwar Kand Chandravir S. Internal Derangement of Temporomandibular Joint: An Evaluation of Effect of Corticosteroid Injection Compared with Injection of Sodium Hyaluronate after Arthrocentesis. J Maxillofacial Surg. 2012; 11(3): 258-63.
2. Kafas P, Leeson R. Assessment of pain in temporomandibular disorders: the bio-psychosocial complexity. Int J Oral Maxillofacial Surg. 2006; 35:145-49.

3. Solberg WK. Temporomandibular disorders: Functional and radiological considerations. $\mathrm{Br}$ Dent $\mathrm{J}$. 1996; 160:195-200.

4. Dulwick MF, Riggs RR. Diagnosis and treatment of internal derangements of the tempor-omandibular joint. Dental Clin North Am. 1983; 27:561-72.

5. Katzberg RW. Temporomandibular joint imaging radiology.1989; 170:297-07.

6. Dworkin SF, Huggins KH, LeResche L, Von Korff M, Howard J, Truelove E, Sommers E. Epidemiology of signs and symptoms in temporomandibular disorders: clinical signs in cases and controls. J Am Dent Assoc. 1990; 120:273-81.

7. Fearon CG, Serwatka WJ. A common denominator for nonorganic TMJ pain-dysfunction.

Prosthet Dent. 1983; 49:805-08.

8. Okeson JP. Management of temporomandibular disorders and occlusion. $5^{\text {th }}$ ed. St. Louis, Mosby; 2003.

9. Nilsson IM, List T, Drangsholt M. The reliability and validity of self-reported temporomandibular disorder pain in adolescents. J Orofacial Pain. 2006; 20:138-44.

10. Reisine ST, Weber J. The effects of temporomandibular joint disorders on patients' quality of life. Community Dent Health. 1989; 6:257-70.

11. Lundh H, Westesson PL, Jisander S, Eriksson L. Disc-repositioning on lays in the treatment of temporomandibular joint disc displacement: comparison with a flat occlusal splint and with no treatment. Oral Surg Oral Med Oral Pathol. 1988; 66:155-62.

12. Greene CS. Managing TMD patients: initial therapy is the key. J Am Dent Assoc.1992; 123:43-45.

13. Kafas P, Chiotaki N, Stavrianos C, Stavrianou I. Temporomandibular joint pain: diagnostic characteristics of chronicity. J Med Sci.2007; 7:1088-92.

14. Mohl ND, Ohrbach RK, Crow HC, Gross AJ. Devices for the diagnosis and treatment of temporomandibular disorders. Part III: Thermography, ultrasound, electrical stimulation, and electromyographic biofeedback. J Prosthet Dent. 1990; 63(4):472-77.

15. Tolvanen M, Oikarinen VJ, Wolf J.A 30-year follow-up study of temporomandibular joint meniscectomies: a report on five patients. Br J Oral Maxillofacial Surg. 1988; 26 (4):311-16. 
16. Mona F, Nagwa E., Dalia E, Adel B. Occlusal splint therapy and magnetic resonance imaging. World Orthod. 2004; 5:133-40.

17. Dylina TJ.A common-sense approach to splint therapy. J Prosthet Dent. 2001; 86:539-45.

18. Conti PC, dos Santos CN, Kogawa EM, de Castro Ferreira Conti AC, de Araujo Cdos R. The treatment of painful temporomandibular joint clicking with oral splints. A randomized clinical trial. J Am Dent Assoc. 2006; 8:1108-14.

19. Raphael KG, Marbach JJ, Klausner JJ, Teaford MF, Fischoff DK. Is bruxism severity a predictor oforal splint efficacy in patients with myofascial face pain? J Oral Rehabil. 2003; 30:17-29.

20. Badel T, Marotti M, Kern J, Laskarin MA. Quantitative analysis of splint therapy of displaced temporo- mandibular joint disc. Ann Anat. 2009; 191:280-7.

21. Bergstrom I, List T, Magnusson T. A follow up study of subjective symptoms of temporomandibular disorders in patients who received acupuncture and /or inter occlusal appliance therapy 18-20 years earlier. Acta Odontol Scand. 2008;66:88-92

22. Wassell RW. The treatment of temporomandibular disorders with stabilizing splints in general dental practice: one-year follow-up., Adams N, Kelly PJ. J Am Dent Assoc. 2006;137 (8):1089-98.

23. Mortazavi ${ }^{1}$ SH, Motamedi MHK, Navi F, Pourshahab M, Bayanzadeh SM, Hajmiragha H, Isapour M. Outcomes of management of early temporomandibular joint disorders: How effective is nonsurgical therapy in the long-term? $\mathrm{N} \mathrm{J}$ maxillofacial surgery. 2010; 1(2): 108-11. 